\title{
Pachydermoperiostosis (PDP): A Case Report
}

\author{
Abdulameer M. Abu Nailah ${ }^{1}$, Islam A. M. Abu-Nayla ${ }^{2}$ and \\ Umniyah A. M. Abu-Nayla ${ }^{3}$
}

\begin{abstract}
Pachydermoperiostosis (PDP) is the primary form of hypertrophic osteoarthropathy which accounts for $5 \%$ of all cases of the disorder. It is a rare hereditary disorder that is associated with digital clubbing, polyarthritis, cutis verticis gyrata, Seborrhea, eyelid ptosis, and hyperhidrosis. In this case report, we discussed a case of an incomplete form of primary hypertrophic osteoarthropathy characterised by evidence of bone abnormalities without pachydermia.
\end{abstract}

Keywords: Pachydermoperiostosis, hypertrophic osteoarthropathy, periostosis.

\footnotetext{
${ }^{1}$ Specialist Rheumatologist MBChB, F.I.C.M, F.I.C.M.S Rheumatology and medicine rehabilitation, MRCP (Rheumatology) Canadian Specialist Hospital, Dubai, UAE.

2 Junior Trainee in Surgery, Addenbrookes Hospital, Cambridge, UK.

3 Medical Intern at Dubai Health Authority, Dubai, UAE.
} 


\section{Introduction}

Pachydermoperiostosis (PDP) is a type of primary hypertrophic osteoarthropathy, a rare inherited disorder, and is characterized by digital clubbing and subperiosteal new bone formation associated with polyarthritis.

Touraine et al. described 3 forms of PDP:

1. A complete form with pachydermia and periostitis.

2. An incomplete form with evidence of bone abnormalities but lacking pachydermia.

3. A forme fruste with prominent pachydermia and less or absent skeletal.

\section{Case Report}

A 39 years old Sri Lankan male patient presented with diffuse joint pain of both knees, ankles, feet, and both hands, with progressive enlargement of both hands and feet for the duration of one month. The patient had a history of the same problem for more than 15 years. The patient also complained of progressive restriction of movement of both of his knees and ankle joints. Morning muscle stiffness was positive apparent for 15 to 20 minutes, along with localised lower back pain.

A blood test was requested from the patient and the results were noted as follows: Normal complete blood count, C- Reactive protein (CRP) levels of 4.7, a Rheumatoid factor of 9.2, and an Erythrocyte Sedimentation Rate (ESR) of 14. Furthermore, the Uric acid level was $6.5 \mathrm{mg}$, the Thyroid-stimulating test result was noted as 1.63 and the Whole abdominal ultrasound was normal.

The X-Ray image of both hands, the knee joint, the ankle joint, and the chest were taken. The X-ray image of the hands showed shaggy subperiosteal new bone formation alongside the distal ends of radius and ulna (extending to involve the epiphyseal margins) and also, but to a lesser degree in the metacarpals and phalanges. Bilateral nearly-symmetrical clubbing of fingers was also observed. No definitive discrete bony erosions or erosive arthropathic changes were seen. 


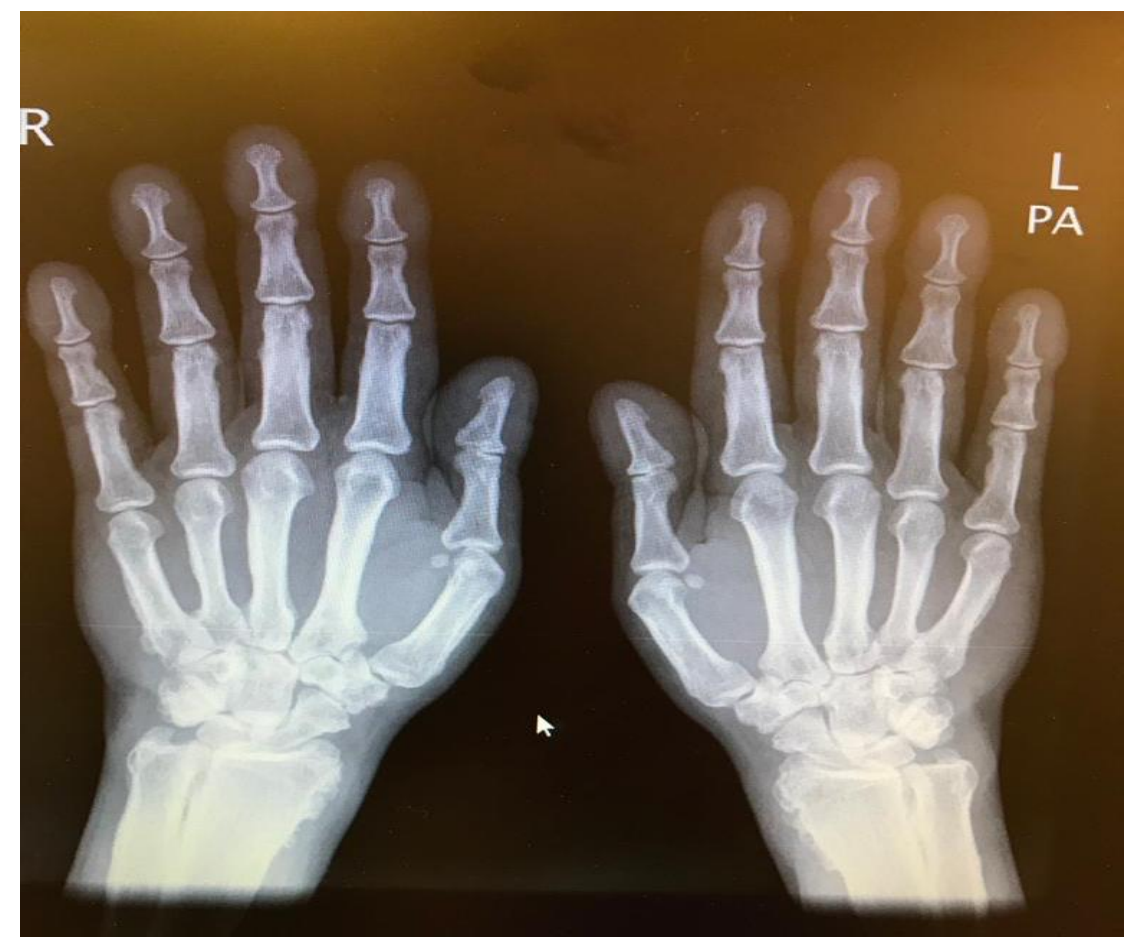

Figure 1: X-Ray of hands shows the subperiosteal new bone formation and bilateral clubbing of fingers

The X-ray image of the knee joints showed heterogeneous irregular periosteal calcification along the diaphyseal and metaphyseal regions of the tibia and femur. 


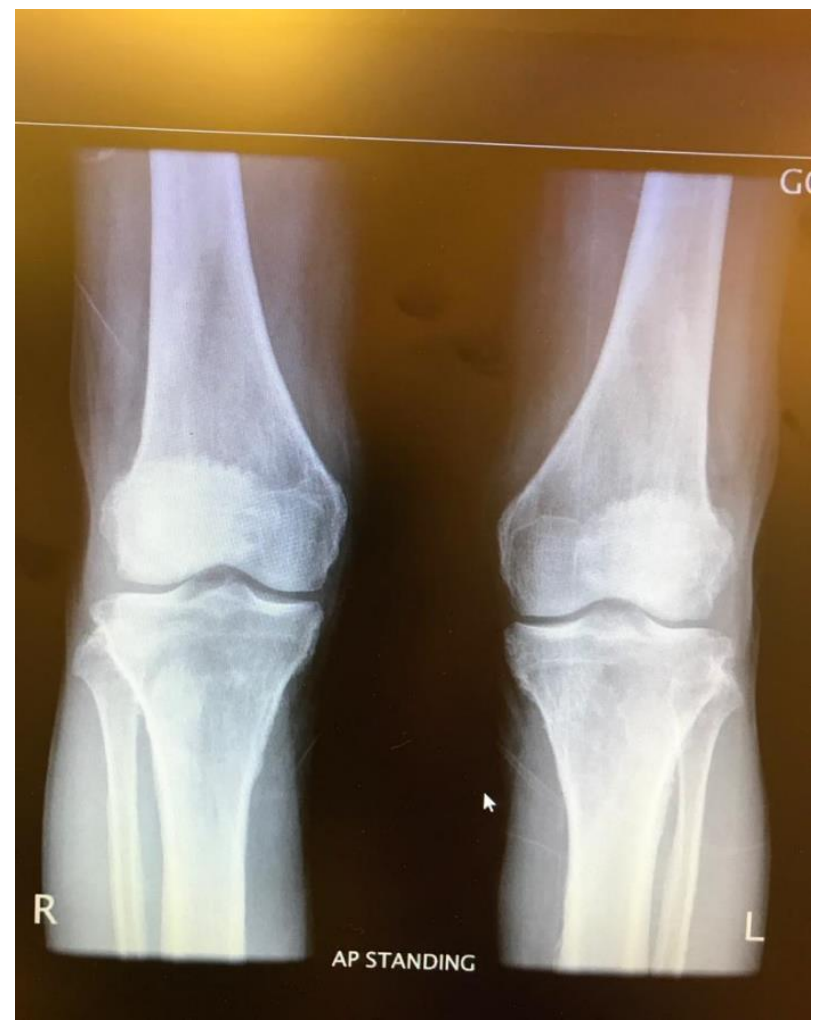

(1)

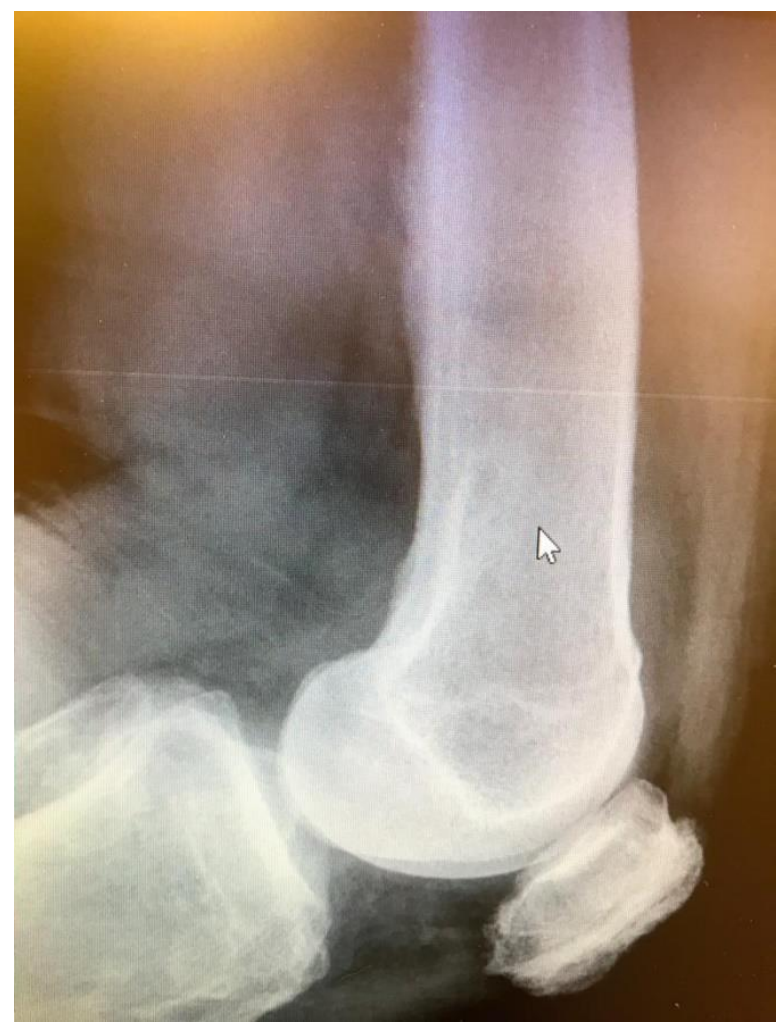

(2)

Figures 2: 1 (on the left) and 2 (on the right), X-ray images of the knee joint showing heterogenous irregular periosteal calcification along with the knee joint.

The X-ray of the ankle joint also showed heterogeneous irregular periosteal calcification seen along the diaphyseal and metaphyseal region of the tibia and fibula observed in figure 4 below: 


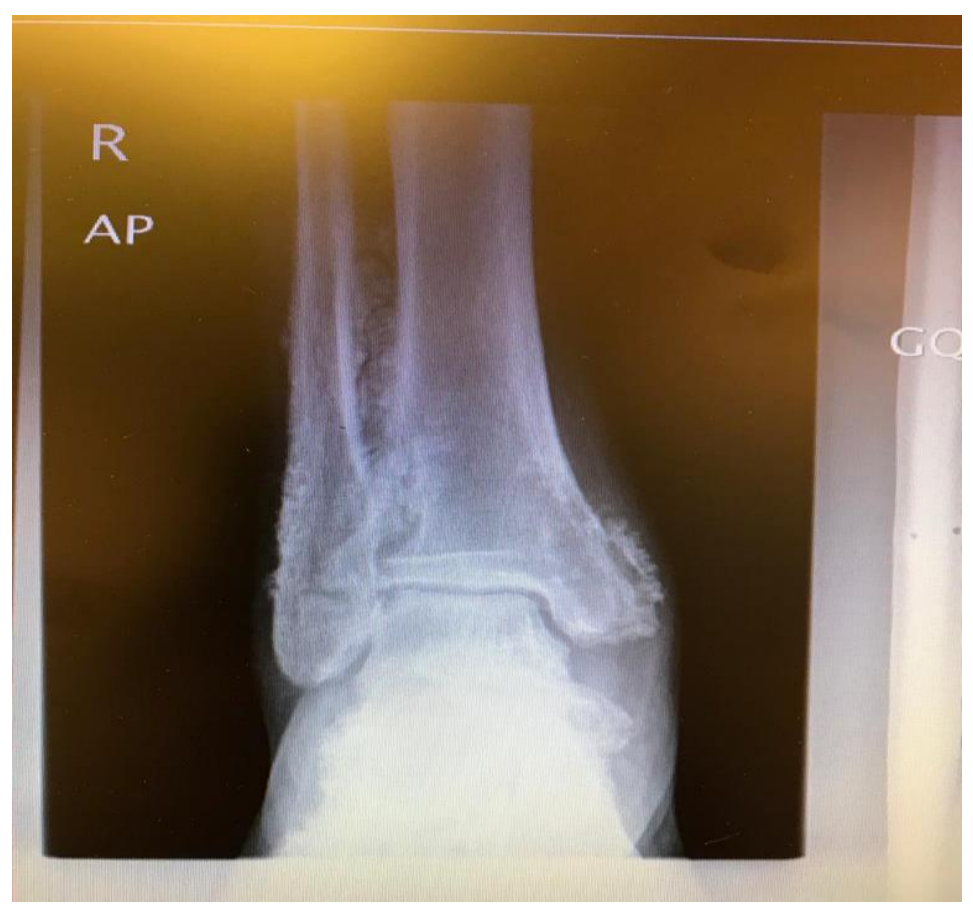

Figure 4: X-ray of the ankle joint showing heterogeneous irregular periosteal calcification seen along the diaphyseal and metaphyseal regions of the tibia and fibula.

The X-ray of the chest (PA view) showed clear lungs felids, normal hilar shadows, clear cardiophrenic, and costophrenic angles. No evidence of pleural effusion was observed. The Cardiac shadow had a normal limit and the Thoracic cage was unremarkable. 


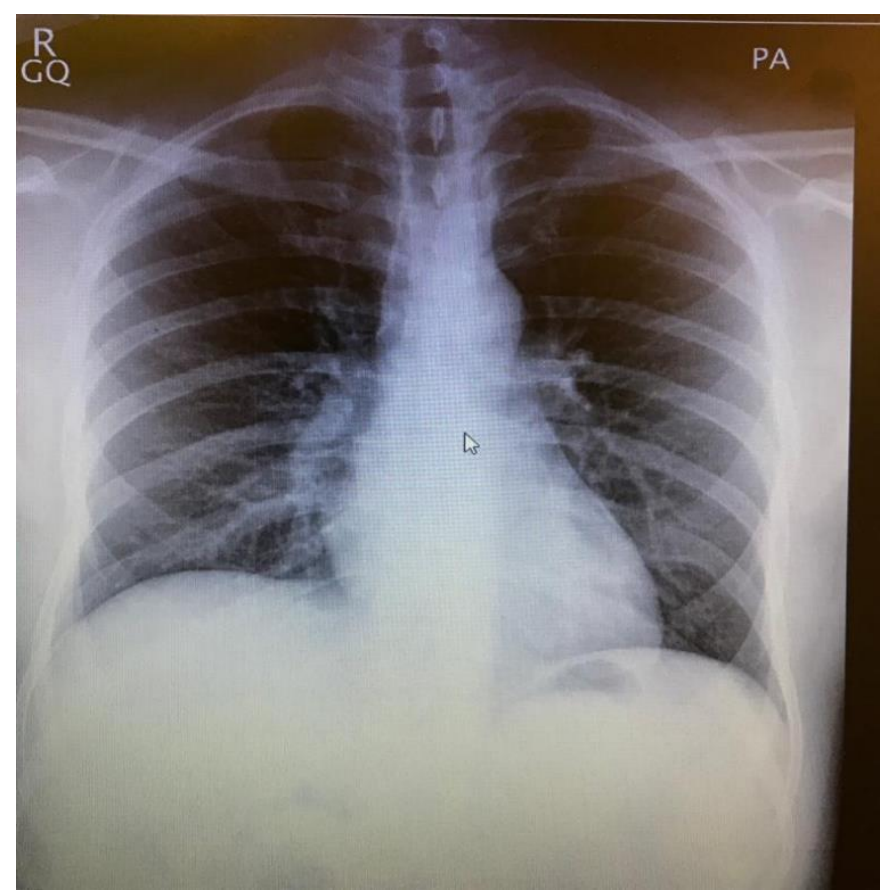

Figure 5: Chest X-ray with clear lung fields, normal hilar shadows, clear cardiophrenic and costophrenic angles.

Furthermore, the Echocardiogram was normal and the abdominal ultrasound was normal.

\section{Discussion}

Pachydermoperiostosis or primary hypertrophic osteoarthropathy is a rare inherited disorder that was first described in 1868. It typically begins during childhood or adolescence and progresses gradually over the next 5-20 years before stabilizing. The disorder has an estimated prevalence of $0.16 \%$. Symptoms usually appear in adolescence, occurring more commonly in males, with a male to female ratio of 7:1. Women usually have a milder condition that can be detected only in X-rays. It is associated with significant morbidity with advancing age.

The aetiology of the disorder is familial and is believed to be inherited in an autosomal dominant or recessive pattern with variable expression. Deficiency of the prostaglandin transporter (SLCO2A1) has been identified as the main cause of primary hypertrophic osteoarthropathy.

Patients with incomplete Pachydermoperiostosis present with digital clubbing, polyarthritis, and subperiosteal new bone formation. The syndrome is characterized 
by abnormal proliferation of the skin and osseous tissue at the distal parts of the extremities.

Radiographs of the long bones reveal fibrous bone growth (periostosis). This feature is mainly seen in the distal tibia, the fibula, the radius, the ulna, the metacarpals, the phalanges, and, less frequently, the metatarsals. Acro-osteolysis and ossification of the ligaments and interosseous membranes may also occur. Periostosis of tubular bones and synovial effusions are most prominent in the large joints and are usually accompanied by pain on palpation of the involved area. Some patients present with a painful arthropathy in advance of clubbing and maybe thought initially to have inflammatory arthritis.

Pachydermoperiostosis has been associated in case reports with a variety of other disorders, including Gastrointestinal pathology (like Gastric carcinoma, Crohn's disease, etc.) Gynecomastia, Hypoplastic internal genitalia, Compressive neuropathy, Osteoporosis, Rheumatoid arthritis, and others.

The progression of Pachydermoperiostosis typically ceases after 10 years. However, complications including severe kyphosis, restricted motion, and neurologic manifestations may persist. Life expectancy may be normal, except in cases where serious neurologic damage is involved.

In certain instances, several years after the onset pachydermoperiostosis or primary hypertrophic osteoarthropathy, diseases generally known to result in secondary hypertrophic osteoarthropathy (Crohn disease, myelofibrosis, and congenital cardiac disease) have been reported to develop in patients with pachydermoperiostosis.

Acknowledgments: We thank the patient and his family members for providing consent and for his participation in the case.

\section{References}

[1] Lowenthal, M. N., Tombak, A. and Lowenthal, A. (2004). Secondary hypertrophic osteoarthropathy (HOA) mimicking primary HOA (pachydermoperiostitis or Touraine-Solente-Golé) syndrome. Isr Med Assoc J. 6 (1):64.

[2] Sandoval, A. R. H., Robles, B. J., Llanos J. C., Porres, S., Dardon, J. D. P. and Harrison, R. M. (2013). Cutis verticis gyrata as a clinical manifestation of Touraine-Solente-Gole' syndrome (pachydermoperiostosis). BMJ Case Rep.

[3] Alves, A. P. X., Filha, J. G. H. and Jeronimo, F. T. (2005). Eyelid ptosis associated with pachydermoperiostosis: case report. Arq Bras Oftalmol. 68(3):401-4.

[4] Arinci, A., Tümerdem, B., Karan, M. A., Erten, N. and Buyukbabani, N. (2002). Ptosis caused by pachydermoperiostosis. Annals Plastic Surgery. 49(3):322-5. 
[5] Touraine, A., Solente, G. and Gole, L. (1935). Un syndrome osteodermopathique: la pachydermie plicaturee avec pachyperiostose des extremites. Presse Med. 43:1820-4.

[6] Jajic, I. and Jajic, Z. (1992). Prevalence of primary hypertrophic osteoarthropathy in selected population. Clin Ex Rheum. 1992;10:73.

[7] Goyal, S., Schwartz, R. A., and Richards, G. M. (2006). Pachydermoperiostosis.

[8] Zhang, Z., He, J. W., Fu, W. Z., Zhang, C. Q. and Zhang, Z. L. (2013). Mutations in the SLCO2A1 gene and primary hypertrophic osteoarthropathy: a clinical and biochemical characterization. J Clin Endocrinol Metab. 98(5):E923-33.

[9] Ayoub, N., Al-Khenaizan, S., Sonbol, H., Albreakan, R., AlSufyani, M. and AlBalwi, M. (2015). A novel homozygous mutation in the SLCO2 A1 gene is associated with severe primary hypertrophic osteoarthropathy phenotype in a Saudi patient.

Int J Dermatol, Jun;54(6):e233-5.

[10] Sahasrabhojaney V. S., Hinge A.V., Ghodeswar S. S., Machnurkar, A. S., Daware, A. M. and Nagarik, A. P. (2005). Touraine-Solente-Gole' syndrome. J Indian Acad Community Med. 2005;6:152-4.

[11] Ikeda, F., Okada, H., Mizuno, M., Kawamoto, H., Okano, N., Okazaki, H., Hamazaki, S. and Shiratori, Y. (2004). Pachydermoperiostosis associated with juvenile polyps of the stomach and gastric adenocarcinoma. J Gastroenterol. 39(4):370-4.

[12] Ukinc, K., Ersoz, H. O., Erem, C., Hacihasanoglu, A., Ersoz, S. and Buran, M. (2007). Pachydermoperiostosis with gynecomastia and osteoporosis: a rare case with a rare presentation. Int J Clin Pract. 61(11):1939-40.

[13] Diamond, S. and Momeni, M. (2007). Primary hypertrophic osteoarthropathy in a patient with rheumatoid arthritis. J Clin Rheumatol. 13(4):242-3.

[14] Martinez-Lavin, M., Vargas, A. and Rivera-Vinas, M. (2008). Hypertrophic osteoarthropathy: a palindrome with a pathogenic connotation. Curr Opin Rheumatol. 20(1):88-91. 